\title{
Factors associated with refusal to treat HIV-infected patients: national survey of dentists in India
}

\author{
Ashish Bodhade, ${ }^{1, *}$, Alka Dive ${ }^{1}$, Shubhangi Khandekar ${ }^{1}$, Akshay Dhoble ${ }^{1}$, Rohit Moharil ${ }^{1}$, \\ Rahul Gayakwad ${ }^{2}$, Satyajit Tekade ${ }^{3}$ \\ ${ }^{1}$ Dept of Oral Pathology, VSPM'S Dental College and Research Center, Nagpur 440019, India \\ ${ }^{2}$ Dept of Public Health Dentistry, SPDC, Sawangi, Wardha, India \\ ${ }^{3}$ Department of Oral and Maxillofacial Pathology \& Microbiology, Modern Dental College \& Research Centre, Nainod, Indore, Madhya \\ Pradesh, India
}

\section{Email address:}

drbodhade55@rediffmail.com (A. Bodhade)

\section{To cite this article:}

Ashish Bodhade, Alka Dive, Shubhangi Khandekar, Akshay Dhoble, Rohit Moharil, Rahul Gayakwad, Satyajit Tekade. Factors Associated with Refusal to Treat HIV-Infected Patients: National Survey of Dentists in India, Science Journal of Public Health. Vol. 1, No. 2, 2013, pp.51-55. doi: 10.11648/j.sjph.20130102.11

\begin{abstract}
Many medical problems are encountered during treatment of oral diseases as well as many oral problems occur due to underlying medical conditions which necessitate modification during dental treatment. Presence of medical problems my require alteration in treatment protocol \& it is combined efforts of medical practitioner and dental surgeon. The present study was designed to assess the causes of distress perceived by Dentists as well as whether there is discriminatory attitudes towards HIV infected patients due to lack of knowledge about how to treat such patients. There should be knowledge, awareness amongst dentist regarding the standard protocol for treatment of patients with medical problems to avoid discrimination and can render possible dental health care.
\end{abstract}

Keywords: HIV Awareness, Dental Education

\section{Introduction}

Many medical problems are encountered during treatment of oral diseases as well as many oral problems occur due to underlying medical conditions which necessitate modification during dental treatment. Presence of medical problems may require alteration in treatment protocol $\&$ it is combined efforts of medical practitioner and dental surgeon [1].

HIV/AIDS is a life-threatening illness that people are afraid of contracting. The various metaphors associated with AIDS have also contributed to the perception of HIV/AIDS as a disease that affects "others," especially those who are already stigmatized because of their sexual behavior, gender, race, or socioeconomic status, and have enabled some people to deny that they personally could be at risk or affected. HIV/AIDS-related stigmatization \& discrimination (S\&D) is, therefore, the result of interaction between diverse pre-existing sources of S\&D and fear of contagion and disease. The pre-existing sources, such as those related to gender, sexuality, and class, often overlap and reinforce one another. This interaction has contributed to the deep-rooted nature of HIV/AIDS-related S\&D, limiting our ability to develop effective responses. It has also created a vicious circle of S\&D, which works in two ways. First, because HIV/AIDS is associated with marginalized behaviors and groups, all individuals with HIV/AIDS are assumed to be from marginalized groups and some may be stigmatized in a way that they were not before. Second, HIV/AIDS exacerbates the stigmatization of individuals and groups who are already oppressed and marginalized, which increases their vulnerability to HIV/AIDS, and which in turn causes them to be further stigmatized and marginalized [2]. This may be the one of the most important factor where medical, dental and allied health staff fears when they encounter these patients.

With the spread of human immunodeficiency virus (HIV) infection dental care workers like Dentists, dental hygienists, dental assistants may fear to contact with people infected with the virus. As reported in the literature, this fearful attitude has greatly contributed to discrimination by some health care workers, including Dentists against HIV-infected persons. However, this discriminatory attitude neither protects the health care worker from possible professional exposure to the virus nor avoids the possibility of cross infection. To avoid this it's necessary to follow standard disin- 
fection and sterilization procedures during routine clinical practice [3].

The present study was designed to assess the causes of distress perceived by Dentists as well as whether there is discriminatory attitudes towards HIV infected patients due to lack of knowledge about how to treat such patients. There should be knowledge, awareness amongst dentist regarding the standard protocol for treatment of patients with medical problems to avoid discrimination and can render possible dental health care.

\section{Materials \& Methods}

A national observational (i. e. , Randomized cross- sectional) survey was conducted with Dentists residing in Indian cities which were gathered in National Indian Dental Conference at Nagpur (Maharashtra) in Central India. Randomly 450 dental practitioners were selected for questionnaire based survey. Informed consent was not requested because it was considered given indirectly when participants completed and submitted questionnaires. Questionnaire was structured to assess the type of dental practice (Private practice or working in institution), the region where dental health care is being provided by the participant (Metro city, District \& Tehsil place), to assess the attitude, awareness \& fear of dental health providers.

\section{Results and Observation}

Total 450 Dentists from all over India were participated in this study. These Dentists were gathered at 62nd, National, Indian Dental Association Conference, 2010, at Nagpur. The questioner was given to assess their awareness, beliefs, attitude towards treating HIV+ve patients who come to their clinics or institution for dental treatment. Out of 450 participants $289(64.2 \%)$ were practicing in metro city, 154 $(34.2 \%) \& 7$ (1.6\%) were from District \& Tehsil places respectively. Out of 450 participants, 301 (66.9\%) were working in Institution while $149(33.1 \%)$ were working in private dental setups.

Amongst 450 respondents, maximum 308(68.4\%) were willing to treat HIV +ve patients. While $142(31.6 \%)$ were still not willing to treat these patients. (Table 1 )

Table 1. Distribution of Dentists preference to treat HIV patient.

\begin{tabular}{llll}
\hline $\begin{array}{l}\text { Dentists preference } \\
\text { to treat HIV patient* }\end{array}$ & Refused & $\begin{array}{l}\text { Not } \\
\text { refused }\end{array}$ & Total \\
\hline Total & $142(31.6 \%)$ & $308(68.4 \%)$ & $450(100.0 \%)$ \\
\hline
\end{tabular}

* Question 1. Dentists preference to treat Patient with HIV infection.

Dentists practicing in metro city and district places significantly willing to treat patients with $\mathrm{HIV}(\mathrm{P}<0.05)$ (Table 2).
Table 2. Proportion of Dentists preference to treat HIV patient according to their region of Dental practice.

\begin{tabular}{llll}
\hline \multirow{2}{*}{ Location of practice } & \multicolumn{2}{l}{$\begin{array}{l}\text { Dentists preference to } \\
\text { treat HIV patient }\end{array}$} & Total \\
\cline { 2 - 4 } & Refused & Not refused & \\
\hline Metro city & $101(22.4 \%)$ & $188(41.8 \%)^{*}$ & $289(64.2 \%)$ \\
District & $41(9.1 \%)$ & $113(25.1 \%)^{*}$ & $154(34.2 \%)$ \\
Tahsil & $0(0.0 \%)$ & $7(1.6 \%)$ & $7(1.6 \%)$ \\
Total & $142(31.6 \%)$ & $308(68.4 \%)$ & $450(100.0 \%)$ \\
\hline & $* P<0.05$ significant. &
\end{tabular}

Out of $149(33.1 \%)$ slightly more $83(18.4 \%)$ dentists from private practice were reluctant to treat HIV patients in their private clinical setups. While dentists practicing in institution were significantly showed willingness to treat patients with HIV $(\mathrm{P}<0.05)$ (Table 3$)$.

Table 3. Proportion of Dentists preference to treat HIV patients according to type of Dental Practice.

\begin{tabular}{llll}
\hline \multirow{2}{*}{ Type of Practice } & \multicolumn{2}{l}{$\begin{array}{l}\text { Dentists preference } \\
\text { to treat HIV patient }\end{array}$} & Total \\
\cline { 2 - 4 } & Refuse & Not refused & \\
\hline Institutional & $59(13.1 \%)$ & $242(53.8 \%)^{*}$ & $301(66.9 \%)$ \\
Private & $83(18.4 \%)^{*}$ & $66(14.7 \%)$ & $149(33.1 \%)$ \\
Total & $142(31.6 \%)$ & $308(68.4 \%)$ & $450(100.0 \%)$ \\
\hline
\end{tabular}

$* P<0.05$ significant

Dentists $\{24(5.3 \%)\}$ who have refused to treat HIV patients did significantly not know that they have ethical responsibility to treat these patients. The dentists $\{215$ $(47.8 \%)\}$ who have not refused to treat HIV patients agreed that they were placed at increased personal risk. Maximum $(61.4 \%)$ dentists agreed that they have to deal with difficulty of fear of dental staff/ assistant regarding HIV/AIDS patients. Those dentists $\{224(49.7 \%)\}$ who have agreed to treat patients with HIV/AIDS thought that other patients may be reluctant to continue in their dental office. Maximum $253(56.8 \%)$ dentists do not think that treating HIV patients will be financial burden on them. Maximum $\{(251(55 \%)\}$ dentists think that they can treat all patients as that of HBV positive while $142(31.6 \%)$ disagrees, that's why they all have refused to treat HIV patients in their dental office. Maximum (73.6\%) dentists think that HBV is more infectious than that of HIV. Maximum $\{224(49.8 \%)\}$ dentists find that infection control practices are not same as that for HBV. Maximum dentists $\{320(73.8 \%)\}$ know that saliva can not readily transmit HIV that is why they did not refuse to treat HIV patients. Risk of transmitting HIV through needle stick injury is minimal i.e. $<1 \%$, is known to very few dentists $\{49(10.9 \%)\}$. Interesting finding is maximum dentists $\{298(66.3 \%)\}$ do not know the nearest ART centers. Nearly all participants agree that they should have knowledge of oral manifestations of HIV infection. (Table 4). 
Table 4. Proportion Associated With Dentists' Preference to Treat Any Patient with HIV Infection.

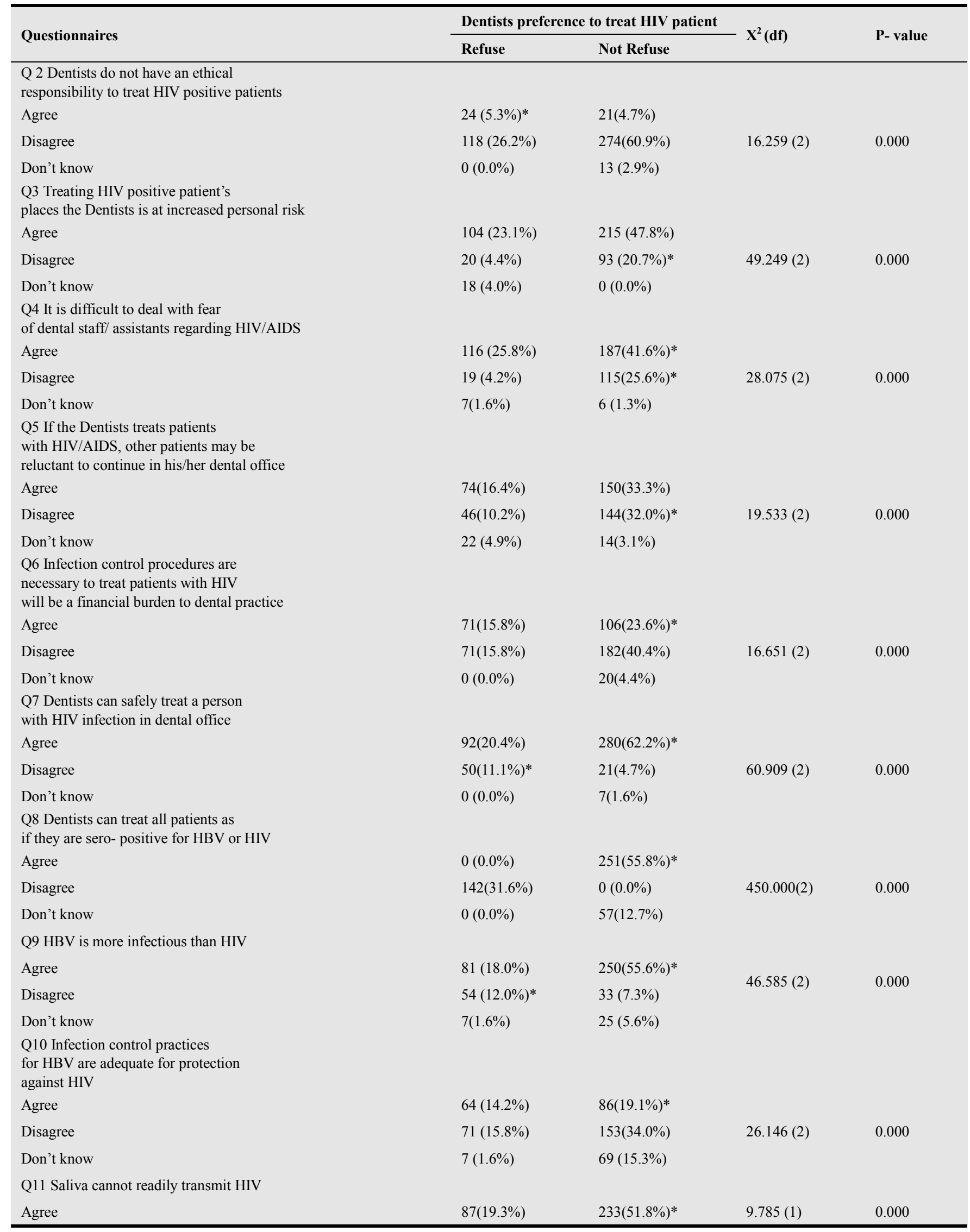




\begin{tabular}{|c|c|c|c|c|}
\hline Disagree & $55(12.2 \%)$ & $75(16.7 \%)^{*}$ & & \\
\hline \multicolumn{5}{|c|}{$\begin{array}{l}\text { Q12 What is the risk of contracting HIV } \\
\text { infection from needle stick injury of HIV- } \\
\text { positive patient? }\end{array}$} \\
\hline$>50 \%$ & $84(18.7 \%)$ & $140(31.1 \%)^{*}$ & \multirow{5}{*}{$35.482(4)$} & \multirow{5}{*}{0.000} \\
\hline $11 \%-50 \%$ & $11(2.4 \%)$ & $77(17.1 \%)^{* *}$ & & \\
\hline $1 \%-10 \%$ & $14(3.1 \%)$ & $27(6.0 \%)$ & & \\
\hline$<1 \%$ & $26(5.8 \%)$ & $23(5.1 \%)$ & & \\
\hline Don't know & $7(1.6 \%)$ & $41(9.1 \%)$ & & \\
\hline \multicolumn{5}{|c|}{$\begin{array}{l}\text { Q13 Are you aware of location of } \\
\text { nearest ART center? }\end{array}$} \\
\hline Yes & $31(6.9 \%)$ & $121(26.9 \%)^{*}$ & \multirow{3}{*}{$13.238(1)$} & \multirow{3}{*}{0.000} \\
\hline No & $111(24.7 \%)$ & $187(41.6 \%)^{*}$ & & \\
\hline \multicolumn{3}{|c|}{$\begin{array}{l}\text { Q14 Dentists should have knowledge } \\
\text { of oral } \\
\text { manifestations of AIDS }\end{array}$} & & \\
\hline Agree & $132(29.3 \%)$ & $308(68.4 \%)^{*}$ & \multirow{3}{*}{$22.183(1)$} & \multirow{3}{*}{0.000} \\
\hline Disagree & $10(2.2 \%)$ & $0(0.0 \%)$ & & \\
\hline Don’t know & $0(0.0 \%)$ & $0(0.0 \%)$ & & \\
\hline
\end{tabular}

$* p<0.05$ significant (Fisher's exact test).

\section{Discussion}

Social and political theory can help us to understand that stigmatization and discrimination are not isolated phenomena or the expression of individual attitudes, but are social processes used to create and maintain social control and to produce and reproduce social inequality [1].

Lack of proper knowledge about AIDS leads to discrimination, stigmatization, and denial (DSD) of the HIV infected patients in society. Discrimination towards HIV/AIDS patients and lack of policies leads to isolation of such patients forcing them to improper care [4]. The health care sector is affected by these DSDs which creates anxiety and fear among people living with HIV/ AIDS (PLHA). Because of this attitude of health care personals PLHA don't disclose their status thinking that it will lead to unpleasant behavior from health care personals $[4,5,6,7]$.

In the present study we tried to analyze the problems arising in the relationship between dentists and HIV-positive patients, as reported from the point of view of the dentists. Because of few Studies in India related to DSDs there it is difficult to understand the means by which such unpleasant behavior can be tackled.

Maximum Dentists $\{308(68.4 \%)\}$ were willing to treat HIV +ve patients while $142(31.6 \%)$ were not willing to treat these patients.

Dentists practicing in metro city and district places significantly reports of willingness to treat patients with HIV $(\mathrm{P}<0.05)$ may be because of emergency facilities readily available at these places.

Slightly more $83(18.4 \%)$ dentists from private practice were reluctant to treat HIV patients in their private clinical setups. Dentists practicing in institutions showed willingness to treat patients with HIV infection significantly $(\mathrm{P}<0.05)$. The dentists who treated HIV patients agreed that they were placed at increased personal risk.

24(5.3\%) Dentists who have refused to treat HIV patients did significantly not know that they have ethical responsibility to treat these patients. Maximum (61.4\%) Dentists agreed that they have to deal with difficulty of fear of dental staff/ assistant regarding HIV/AIDS patients. 224(49.7\%) dentists agree that if they treat patients with HIV/AIDS, other patients may be discontinue treatment in their dental office. Interesting finding is maximum no [298 (66.3\%)] of dentists do not know the nearest ART centers. Nearly all participants agree that they should have knowledge of oral manifestations of HIV infection. From this it is necessary to spread HIV awareness in dental professional.

According to Indian dental association a Dentists has the general obligation to provide care to those in need. It is unethical to deny treatment to an individual infected with Human Immunodeficiency Virus, Hepatitis B Virus, Hepatitis C Virus or another blood borne pathogen [8]. Treatment planning should not differ for infected and non -infected patients; perhaps they should be dealt with a sympathetic approach. Decisions with regard to the type of dental treatment provided or referrals made or suggested should be made on the same basis as they are made with other patients. The dentists should determine if they need any other skill, knowledge, equipment or experience. Current guidelines are that Dentists must not refuse to treat a patient solely on the grounds of HIV infection [9].

\section{Conclusion}

Refusal to treat patients with HIV was primarily associated with lack of ethical responsibility and fear related to cross-infection. In addition to increased emphasis on infection control and knowledge of infectivity of blood-borne pathogens, teaching of biomedical ethics at the undergra- 
duate and postgraduate level and in continuing dental education may reduce dentist's refusal to treat HIV-infected patients.

Refusal to treat is largely related to risk of cross infection. This fear is mostly because of lack of proper knowledge to deal with such patients. Though in present study maximum dentists have shown awareness and inclination to treat these patients, still a few dentists hesitate to treat such patients. Such class of dentists needs to be made aware about the care to be taken while treating such patients and should be motivated to treat PLHA.

\section{Acknowledgements}

DR Usha Radke,

Dean, VSPM'S DCRC, Nagpur.

Dr Abhay Kolte,

Prof \& HOD, Dept of Periodontia, VSPM'S DCRC, Nagpur. (Conference Secretary, 62nd Indian Dental Conference, Nagpur)

\section{References}

[1] Gill Y, Scully C. Attitudes and Awareness of Final-Year Predoctoral Dental and Medical Students to Medical Problems in Dentistry. Journal of Dental Education 2006; 70(9):991-995.
[2] Malcolm A. et al. HIV and AIDS-related stigmatization and discrimination: its form and contexts. Critical Public Health 1998; 8(4):347-370.

[3] McCarthy GM, Koval JJ, MacDonald JK. Factors associated with refusal to treat HIV- Infected patients: The results of a National survey of dentists in Canada. Am J Public health 1999:89;541-545.

[4] Giuliani M, Lajolo C, Sartorio A et al. Attitudes and practices of Dentists treating patients infected with human immunodeficiency virus in the era of highly active antiretroviral therapy. Med Sci Monit 2009; 15(6): 49-56.

[5] Bharat S, Aggleton P and Tyrer P. India: HIV and AIDS-related Discrimination, Stigmatization and Denial. UNAIDS/01.46E, August 2001.

[6] Bharat S (1996). Facing the challenge: household and community response to HIV/AIDS in Mumbai, India. Geneva, UNAIDS / Mumbai, TISS.

[7] Tirelli U, Accurso V, Spina M, Vaccher E (1991) HIV and discrimination. British Medical Journal, 303:582.

[8] Code of ethics. Indian dental Assosiation. Avilable at http://www.ida.org.in/AboutIDA/CodeOfEthics.aspx.

[9] Prabhu SR, Kohali A. Ethical issues in dental practice. In textbook of HIV/AIDS IN DENTAL PRACTICE. Handbook for Dental Practitioners in India. A Publication of the Dental Council of India. Edited by Prabhu SR, Kohali A, C Bhaskar Rao. Printed at Thompson press India, 2007; 267. 